\title{
Marketing untuk Menghadapi Masyarakat Ekonomi Asean (MEA)
}

\author{
Achmad Yusron \\ Fakultas Ekonomi, IAIN Palangka Raya, Jl. George Obos Komplek Islamic Center, Palangka Raya, 73111 \\ E-mail: yusiborneo594@gmail.com
}

\begin{abstract}
A "whole" marketing process must take into account the transcendental element. Because, even though the marketer has been able to make customer smiles but with his actions to anger God the customer (Allah SWT). To speed up the economy in a country even to do international cooperation. MEA is a form of ASEAN economic integration in the sense that there is a free system among ASEAN countries. Indonesia and nine other ASEAN member countries agreed on the ASEAN Economic Community (MEA) Agreement. All ASEAN member countries will soon face a single, open market based on production. The establishment of the MEA aims to improve the welfare of all ASEAN members to face bank interest. It requires inter-sectoral policy coordination to seek solutions to prepare competit- able national industries. ASEAN needs to develop and have a competitive strategy. ASEAN needs to develop and have a great strategy and welcome MEA.
\end{abstract}

Keywords - : Marketing Islamic; Asean Economic Community.

\section{PENDAHULUAN}

Suatu proses marketing yang "utuh" harus memperhitungkan unsur transendental ini. Karena, sekali pun marketer telah mampu membuat senyum pelanggan, tetapi dengan tindakannya membuat marah Tuhan (Allah SWT). Maka, marketer telah memasarkan dengan gagal. Jika ia telah memasarkan memuaskan sekelompok orang pria terpuaskan tetapi strategi pemasaran menurunkan derajat wanita (dengan mengumbar lengkuk tubuhnya), maka itu memasarkan dengan gagal. Syariah marketing mengajarkan bahwa responsibilitas seseorang pemasar belum akan berakhir sebelum dia mampu mempertanggungjawabkan segenap produk dan proses pemasaran dihadapan Allah SWT di pandang mahsyar nanti. Karena, dialah Tuhan bagi segenap nasabah, karyawan, generasi penerus, pemerintah dan masyarakat. Syariah marketing harus bertumpu pada empat prinsip dasar Ketuhanan (rabbaniyyah), menjunjung akhlak tinggi mulia (akhlaqiyyah), mewaspadai pasar yang selalu berubah (waqi'iyah), dan selalu berorentasi untuk memartabatkan manusia (al-insaniyyah). Hermawan dan Syafi'i (2006) menunjukkan tujuh belas strategi untuk mengimplementasikan prinsip-prinsip diatas. Strategi tersebut antara lain meliputi: mengembangkan spritualbased organisation, menunjukan respek yang tinggi terahadap pesaing, mencermati global paradoks nasabah, harus jeli dalam menentukan ceruk pasar (segmentation), mampu mencuri hati dan jiwa nasabah (customer's heart and soul) yang mampu untuk menjadi beda dalam hal konten dan kontek penggarapan pasar, bersikap transparan, mengayuhkan nilai tambah yang proporsional kepada segenap stakeholders, jujur dalam memberikan marketing-mix (barang, harga, promosi, pengiriman, dan layanan purna-jual) serta mengembangkan budaya yang etis dan bermoral. Supaya bisa dijadikan pedoman untuk pemasaran secara islami yang benar. Oleh karena itu islamic marketing dijadikan pedoman untuk menghadapi Masyarakat Ekonomi ASEAN. Supaya kita bisa mengatasi hal-hal yang tidak diinginkan. Kita harus punya pondasi yang kuat dalam menghadapi Masyarakat Ekonomi ASEAN.

Demikian juga perjalanan menghadapi Masyarakat Ekonomi ASEAN, ada transisi dalam marketing dari rasional ke emosional, kemudian ke spritual. Oleh karena itu tidak mengherankan mengapa Stephen R, Covey menyusun buku "The 7 Habit of Highly Effective people the way”. Ekonomi islam mengalami perkembangan yang sangat luar biasa. Berkaitan dengan ini wilayah Asia Tenggara dapat disebut sebagai rumah produksi bagi keahlian dan inovasi. Asia Tenggara dengan mayoritas penduduk muslim, memang menjadi perhatian internasional. Kita bisa melihat perkembangan ekonomi islam berkembang baik sebagai ilmu pengertahuan maupun sebagai sebuah sistem. Implementasi islamic marketing dapat dilihat dari Masyarakat Ekonomi Asia, khususnya di Indonesia, Presiden mempunyai program untuk menghadapi Masyarakat Ekonomi ASEAN. Kebebasan masyarakat Ekonomi ASEAN ini harus benar-benar ditangani sebaik mungkin. Agar ekonomi di Indonesia khususnya tetap stabil. Kemungkinan kalau tidak mampu bersaing Masyarakat Ekonomi ASEAN ini bisa tidak bisa harus dihadapi dengan baik. Untuk mempercepat perekonomian di suatu negara bahkan sampai melakukan kerja sma internasional.

MEA adalah bentuk integrasi ekonomi ASEAN dalam arti adanya sistem perdanagan bebas antara negara-negara ASEAN. Indonesia dan sembilan negara anggota ASEAN lainnya menyepakati perjanjian Masyarakat Ekonomi ASEAN (MEA). Melihat pesatnya ini penulis sangat tertarik untuk meneliti perkembangan "islamic marketing untuk menghadapi Masyarakat Ekonomi ASEAN" penulis akan merumuskan pembahasan yang akan dibahas yaitu, pertama, bagaimana tantangan Islamic Marketing dalam menghadapi Masyarakat Ekonomi ASEAN. 
Website : http://ekomaks.unmermadiun.ac.id/index.php/ekomaks

\section{METODE PENELITIAN}

Pendekatan yang dipakai dalam penulisan ini adalah pendekatan deskriptif (studi kepustakaan). Studi kepustakaan adalah segala usaha yang dilaksanakan untuk menghimpun informasi yang relevan dengan topik atau masalah yang dibahas. Informasi itu dapat diperoleh dari jurnal ilmiah, laporan penilitian, tesis dan disertasi, peraturan-peraturan, ketetapan-ketetapan, buku tahunan, ensikplodia, dan sumber-sumber tertulis lain baik tercetak maupun elektronik.

Penentuan informasi dalam penelitian ini dengan cara pengumpulan data dan informasi tentang Islamic Marketing untuk mengahadapi Masyarakat Ekonomi ASEAN.

\section{III.HASIL DAN PEMBAHASAN}

Dalam bahasa syariah, spiritual marketing adalah tingkatan "pemasaran langit" yang karena di dalam keseluruhan prosenya tidak ada yang bertentangan dengan prinsip-prinsip mualamalah (bisnis syariah) ia mengandung nilai ibadah yang menjadikannya berada pada puncak tertinggi dalam pemasaran atau muamalah. Seorang muslim yang baik, dalam transaksi muamalahnya dalam hal ini pemasarannya baik sebagai pemimpin perusahaan, pemilik, pemasar, pesaing, maupun sebagai pelanggan hendaklah prinsip-prinsip keadilan, kejujuran, transparansi, etika dan moralitas. Hal ini bisa dijadikan landasan untuk menuju pemasaran yang mempunyai asumsi Islamic Marketing. Akan tetapi setiap orang muslim hendaknya harus bisa mengupayakan hal yang benar-benar yang sudah di ajarkan oleh Rosullullah SAW, oleh karena itu mari kita harus bisa menjadi orang yang mempunyai dasar Islami yang kuat.

Islam adalah agama yang diajarkan oleh Nabi Muhammad SAW. Berpedoman pada kitab suci Al-Quran yang diturunkan ke dunia melalui wahyu Allah Swt. Pemasaran penilaian strategi pemasaran, jasa, fungsi, dan hasilnya (KBBI). Bauran pemasaran Islami merupakan tools yang terdiri dari produk, harga, lokasi, promosi, SDM, proses dan sarana fisik. Dalam pandangan Farrel (2001), pemasaran merupakan area fungsional utama dalam organisasi bisnis yang menyediakan pertemuan bukan hanya para pelanggan, tetapi juga dengan pemangku kepentingan, seperti media, investor, lembaga regulator, stasiun televisi, asosiasi perdagangan, dan lainnya. Adapun menurut Kotler dan Keller (2009), pemasaran adalah fungsi organisasi dan seperangkat proses untuk menciptakan, mengkomunikasikan, dan memberikan nilai pelanggan, dan untuk mengelola hubungan pelanggan dengan cara yang menguntungkan organisasi dan para pemangku kepentingan.

Adapun konsep Pemasaran Islam dapat dianalisis dan dibangun dari filosofi yang bersumber pada tujuan motif dasar pada penciptaan manusia. Islam merupakan agama yang lengkap dan mengatur kehidupan manusia (QS3: 19, QS 16: 52, QS98: 5, dan QS110: 2). Beberapa ayat Al-Quran tersebut menekankan pentingnya kesejahteraan bagi kehidupan pengatur alam raya ini. Semua aspek kehidupan manusia termasuk kegiatan bisnis dan pemasaran harus mengikuti ketentuan yang ditetapkan oleh Allah. Dalam islam pemasaran tidak terbatas pada penjualan atau pencitraan untuk mendapatkan keuntungan dari barang dan jasa pada semua tingkat bisnis. Konsep utamanya berupa ketentuan bahwa semua kegiatan dan transaksi dianggap sebagai ibadah (QS2: 30), termasuk hal-hal yang telah dijelaskan dan dipraktikkan oleh Nabi Muhammad SAW. Misalnya ketentuan tentang makanan yang bertujuan untuk meningkatkan kesejahteraan manusia (QS5: 48) (Abuznaid, 2012).

Prinsip pemasaran Islam menggabungkan konsep maksimalisasi nilai dengan prinsip keadilan untuk kesejahteraan yang lebih luas dari masyarakat. Prinsip-prinsip ini menawarkan cara untuk menciptakan nilai dan meningkatkan standar hidup pada umumnya melalui kegiatan komersial. Pedoman etika Islam mengatur bahwa pemasaran dilarang mengeksploitasi pelanggan, atau dengan cara apapun untuk melibatkan diri dalam ketidakjujuran, penipuan atau kebohongan. Praktik pemasaran yang tidak etis seperti perbuatan tidak adil, meniadakan konsep persaudaraan dan persamaan kemanusiaan yang membentuk inti dari visi Islam (Saeed, Ahmad dan Mukhtar, 2001). Dengan demikian, ketika pemasaran Islam menekankan tercapainya peningkatan martabat dan menjunjung tinggi hak asasi manusia.

Arham (2010) berpendapat bahwa konsep pemasaran Islam berdasarkan filosofi untuk mengidentifikasi elemen-elemen dalam cakupan pemasaran Islam. Ada empat karakteristik utama dalam pemasaran Islam, yaitu spiritual, etika, realistis, dan humanistik. Adapun Sula dan Kartajaya (2006) memberikan model pembentukkan pemasaran Islam yang diindetifikasi memiliki 4 kontruksi dan 17 elemen sebagai prinsip-prinsip inti dari Pemasaran Islam, sebagaimana berikut ini:

\begin{tabular}{|l|l|}
\hline \multicolumn{1}{|c|}{$\begin{array}{c}\text { Kontruksi Prinsip-prinsip Pemasaran } \\
\text { Islam }\end{array}$} & \multicolumn{1}{c|}{ Elemen } \\
\hline Lanskap pemasaran Islam & Teknologi informasi yang mewujudkan transparansi \\
& Menghormati pesaing \\
& Munculnya pelanggan akibat paradoks global \\
& Mengembangkan organisisi berbasis spritual \\
\hline Elemen-elemen arsitektur bisnis strategis & Mengamati kondisi pasar secara universal \\
& Meraih hati dan jiwa pelanggan \\
& Membangun sistem kepercayaan \\
& Komitmen diri dengan paket pada konten dan konteks yang \\
& baik \\
& Jujur dengan 4P \\
& Menciptakkan keakrapan \\
& Menggunakan karakter merek yang bersifat spritual \\
& Jasa harus memiliki kemampuan untuk perubahan \\
\hline
\end{tabular}


Website : http://ekomaks.unmermadiun.ac.id/index.php/ekomaks

\begin{tabular}{|l|l|}
\hline & Mempraktikan proses bisnis yang handal \\
\hline Standar penilaian syari'ah & Menciptakan nilai bagi para pemangku kepentingan \\
\hline Pemasaran perusahaan syariah & $\begin{array}{l}\text { Menciptakkan tujuan yang mulia } \\
\text { Mengembangkan budaya perusahaan yang etsi } \\
\text { Pengukuran harus jelas dan transparan }\end{array}$ \\
\hline
\end{tabular}

Kotler dan Amstrong (2006) menegaskan pula bahwa program pemasaran yang efektif memadukan semua elemen marketing mix ke dalam program yang dirancang untuk mencapai tujuan pemasaran perusahaan dengan memberikan nilai kepada pelanggan. Bauran pemasaran mencakup segala sesuatu yang dilakukan perusahaan dalam memengaruhi permintaan terhadap produk-produknya. Alizade, Mehrani dan Dedekhani (2014) menerangkan bahwa bauran pemasaran merupakan serangkaian instrumen pemasaran yang menggunakkan perusahaan untuk mencapai tujuan pemasaran pada sasaran pasar. Dalam pandangan Rofiq dan Ahmed (1995), hal itu sebagai salah satu konsep inti dari teori pemasaran. Hassan dan Latiff (2008) menerangkan bahwa komponen bauran pemasaran mungkin berbeda sesuai dengan persepsi konsumen, perilaku, konsumen, karakteristik, budaya, agama, politik, dan kebiasaan. Oleh karena itu, humas pemasaran secara etika mencakup nasabah memiliki kebebasan pengambilan keputusan yang harus dilindungi dari semua unsur pemaksaan.

Pemasaran (marketing) adalah suatu metode baru untuk memajukkan dan mengembangkan potensi sebuah organisasi atau lembaga pendidikan. Pemasaran (marketing) merupakan proses perencanaan dan pelaksanaan konsepsi harga, promosi dan distribusi ide-ide, barang-barang dan jasa untuk membuat pertukaran yang memuaskan tujuan-tujuan individu dan organisasi.

\section{A. Latar Belakang dan Sejarah MEA}

Diawali dari perjanjian bersama pada tingkat Konferensi Tingkat Tinggi (KTT) yang digelar di Kuala Lumpur, Malaysia yang menghasilkan satu misi berrsama negara-negara ASEAN (ASEAN Vision 2020). Tujuannya menjadikan kawasan Asia Tenggara sebagai kawasan yang makmur dengan pembangunan serta pengembangan ekonomi yang menjadi anggotanya. KTT di Bali, Indonesia pada Oktober 1997. Pada KTT di Bali tersebut, para pemimpin negara-negara ASEAN menyatakan pentingnya mengintegrasikan Masyarakat Ekonomi ASEAN (MEA) sebagai satu tujuan utama dalam integrasi perilaku ekonomi di kawasan regional yang akan diterapkan Tahun 2020.

KTT selanjutnya di Kuala Lumpur, Malaysia melahirkan konsensus baru. Isinya menyatakan bahwa tahun diberlakukannya MEA dimajukan. Yang awalnya tahun 2020 menjadi tahun 2015. Konsensus tersebut melahirkan deklarasi Cebu. Dengan ditanda tangan Cebu maka keputusan konsensus dari tahun ke tahun menjadi satu langkah nyata untuk menjadikan ASEAN sebagai daerah perdagangan bebas yang meliputi seluruh komponen aktivitas ekonomi. Mulai dari barang, tenaga kerja (terampil), investasi, modal, sampai jasa.

\section{B. Tujuan dari dibentuknya MEA}

Seperti yang dijelaskan pemerataan ekonomi bagi seluruh warga Masyarakat kawasan ASEAN. Jika diuraikan berdasarkan deklarasi Cebu, tujuan utama dari dibentuknya Masyarakat Ekonomi ASEAN (MEA), yaitu:

1) Menciptakan pasar tunggal yang mencakup negara-negara ASEAN sekaligus pusat produksi dengan kaitan pada elemen produk aktivitas ekonomi bebas, seperti tenaga kerja(terdidik/terampil), bebas bea untuk aliran barang dan jasa dari kawasan regional ASEAN, serta keluar masuknya investasi dan aliran modal umntuk negara-negara sekawan.

2) Menjadikan ASEAN sebagai kawasan berdaya saing ekonomi meliputi perlindungan konsumen, hak atas kekayaan intelektual (HAKI), perpajakan, kelancaran aktivitas $e$-commerce dan pengembangan infrastruktur.

3) Meratakan pemberdayaan ekonomi kawasan ASEAN dengasn sasaran utama revilitas usaha kecil dan menengah (UKM), tertuma bagi negara Kamboja, Nyanmar, Laos, dan Vietnam. (CMLV) telah lama dan berulang kali didera dengan beragam masala politik, ekonomi, budaya yang berpengaruh terahadap keamanan negara tersebut.

Mengintegrasikan ekonomi kawasan dengan ekonomi global dengan tujuan dasar untuk meningkatvkan peran serta ASEAN dalam percaturan kebijakan globbal. Hal ini tentu adalah salah satu sisi positif sebab nantinya negara-negara ASEAN dianggap penting.

Tujuan pembentukan dari MEA sesuai dengan deklarasi Cebu tersebut tentu memberikan corak baru bagi ciri ekonomi di kawasan MEA. Ciri tersebut bisa dijabarkan sebagai berikut:

1) Iklim ekonomi kawasan menjadi lebih kompetitif.

2) Usaha untuk pemerataan ekonomi dalam ruang limgkup negara-negara yang tergabung dalam ASEAN.

3) Integrasi ekonomi global dan pelosok untuk menjadi basis produksi serta pasar tunggal.

Mengingat betapa besar tujuan besar serta ketatnya corak ekonomi global kawasan MEA, tentu dirasa perlu bagi masyarakat Indonesia untuk tahu lebih jauh seluk beluk di balik MEA serta manfaatnya. Informasi-informasi yang beredar tentang globalisasi yang menampilkan sisi negatif terkadang menjadikan orang takut untuk berhadapan atau menimbulkan rasa tidak percaya diri. Terlebih mengenai isu ketatnya persaingan dalam bidang ketenagakerjaan. Namun sebenarnya tak perlu bersikap demikian apalagi termakan isu yang ada lima hal yang perlu diketahui agar lebih mantap dalam mempersiapkan diri dan berani menghadapi persaingan secara global, yaitu:

1) MEA bukanlah baru dalam lingkup ASEAN

Berdasarkan sejarah, kebijakan ASEAN untuk bersatu dalam mewujudkan perdagangan bebas MEA bukanlah hal baru. Setidaknya semua sudah terencana selama kurang lebih satu dekade belakangan. 
Website : http://ekomaks.unmermadiun.ac.id/index.php/ekomaks

2) MEA memberi banyak keuntungan yang di dapat individu

Salah satu tujuan MEA adalah mengusahakan pemerataan dan menurunkan ketimpangan dalam masyarakat ASEAN. Seperti yang sudah disinggung sebelumnya tentang kemajuan UKM di negara negara ACMLV. Lalu apa keuntungannya untuk masyarakat Indonesia? MEA akan menjadikan ASEAN sebagai pasar atau produsen dari berbagai prioduk negaranegara anggota.

3) Produktivitas dan cross market

Pasar memiliki tingkat kejenuhan sendiri. Dengan MEA pasar yang terbuka semakin luas, demikian pula dengan kompetisi. Yang harus menjadi fokus tentu saja adalah bagaimana masuknya negara lain. Semakin daya saing (karena kualitas) membuat produsen lebih kreatif dan inovatif serta berkualitas dalam menciptakan produk.

4) Kesadaran akan meningkatkan mutu SDM

Data dari 2014, menunjukan jumlah pekerja berpendidikan sekolah menengah pertama (SMP) di Indonesia sekitar 76,4 juta jiwa. Tersebut jika dipersenkan sekitar 64\% dari 118 juta jiwa pekerja Indonesia. Angka yang termasuk tinggi untuk indikator rendahnya mutu Sumber Daya Manusia (SDM) yang dimiliki. Setiap individu yang sadar dengan persaingan MEA tentu akan terus menggenjot mutu dan tingkat pendidikan sampai ke level tinggi.

5) Kesadaran akan peningkatan infrastruktur dan sarana pendukung

Negara dapat berkembang menuju signifikan dengan mendorong pembangunan di bidang sarana dan prasarana. Dibukanya MEA juga merasakan hal yang sama. Tentu butuh peran serta semua pihak agar sarana dan prasarana di Indonesia terus berkemabang.

Masyarakat ASEAN bukanlah momok yang perlu diikuti. Sebab ini tak lain hanya keniscayaan globalilsasi itu sendiri. Memahami sistem dan skema MEA serta mempersiapkan diri menghadapi dan membuat kita punya andil untuk mendukung program ini agar berjalan dengan baik. Setiap kebijakan biasanya juga perlu diantisipasi sehingga bisa mengikuti MEA dengan baik.

\section{Segera Susun Strategi}

Semua negara anggota ASEAN tidak lama lagi akan menghadapi pasar tunggal dan terbuka yang berbasis produksi. Pembentukan MEA tersebut bertujuan untuk meningkatkan kesejahteraan seluruh anggota ASEAN untuk menghadapi bunga bank. Diperlukan koordinasi kebijakan antar sektor untuk mencari jalan keluar guna mempersiapkan industri nasional yang memiliki daya saing. Indonesia perlu menyusun dan memiliki strategi daya saing. Indonesia perlu menyusun dan memiliki strategi besar serta menyambut MEA. Strategi inilah yang nantinya menjadi bahan rujukan melakuakan langkah aksi menghadapi MEA bagi segenap pemangku kemenamgan. Salah satu strategi yang bisa dipertimbangakan yaitu memilih salah satu dari dua belas sektor prioritas MEA (produk pertanian, produk perikanan, angkutan udara, otomotif, elektronik, logistik, pariwisata, dan $e-A S E A N$ ) untuk dijadikan prioritas. Sektor pariwisata misalnya, bisa diusung karena punya keunikan dan keberagaman budaya panorama alam. Agar sektor ini memiliki daya saing, perlu didukung dengan transportasi infrakstruktur, SDM pariwisata yang handal, dan kesediaan jasa keuangan di lokasi tujuan wisata.

Semua pemangku kepentingan baik pusat maupun daerah menjadi penting untuk menyiapkan langkah-langkah dalam menghadapi MEA. Hal ini dimaksudkan agar keduanya memiliki peran intergratif dalam menghadapi MEA. Disamping itu, diharapkan dengan adanya kerja sama pemerintah daerah, dapat terbangun sinergisitas yang hasilnya tidak dirasakan oleh satu pihak, melainkan dapat dimanfaatkan secara nasional. Meskipun yang tersedia fasilitas pengembangan industri berorentasi ekspor, peningkatan kualitas SDM daerah dengan menyelenggarakan daerah yang lebih kondusif dengan meninjau ulang pengaturan upah minimum Provinsi/Kabupaten/Kota, dan melakukan sinergi serta sinkronisasi antara strategi dan program swasta dalam mencermati dan memanfaatkan pasar ASEAN.

\section{Harus Selalu Bisa}

Ketatnya persaingan usaha di dalam negeri tidak terlepas dari besarnya potensi Indonesia di mata negara tetangga. Indonesia saat ini menyumbang 40\% PDB dan penduduknya mencapai 50\% atas keseluruhan penduduk ASEAN. Ditopang konsumsi domestik, ekonomi Indonesia tumbuh solid di tengah krisis global. Belum lagi kenyataan bahwa dengan menjaga kekuatan kelas menengah, Indonesia menyalip Inggris dan menjadi kekuatan ekonomi nomor tujuh dunia pada tahun 2030. Bayangkan bagaimana negara tetangga yang pasar domestiknya terbatas dan potensinya pertumbuhan mendekati puncak tidak tergiur mengincar kita. Indonesia ibarat kembang desa yang menarik para pemuda desa tetangga. Memang MEA menjanjikan manfaat bagi Indonesia baik dari sudut pandang sebagai ASEAN maupun secara individu negara. Dari sudut pandang kawasan dengan penduduk 588 juta jiwa dan PDB nominal US\$2,1 milyar, ASEAN menawarkan skala ekonomi untuk mampu bersaing dengan Cina dan India. Integrasi ekonomi juga mendorong aliran investasi dan perdagangan antara negara anggota yang lebih tinggi sehingga dapat memunculkan perusahaan-perusahaan kawasan yang mampu bersaing secara global. Dari sudut Indonesia sendiri persaingan ketat di pasar domestik pada pasarnya menguntungkan konsumen berkat tawaran variasi dan kualitas barang dan jasa yang lebih kaya dan berharga kompetitif. Integriasi ekonomi juga memberi manfaat nyata bagi konsumen, produsen dan juga ekonomi secara keseluruhan. Tapi manfaatnya bagi produsen kita semua mampu bersaing dalam MEA. Bila tidak berdaya saing, mereka terancam tersingkir dan bahkan gulung tikar. Selain itu, ekonomi Indonesia secara keseluruhan mengambil manfaat apabila produsen kita memenangkan persaingan. Kemenangan itu memberi kesempatan produsen itu untuk menyerap lebih banyak tenaga kerja dan mengurangi pengangguran. Laba yang diperoleh juga menambah konsumsi dan 
Website : http://ekomaks.unmermadiun.ac.id/index.php/ekomaks

investasi di perekonomian. Selain bernilai tambah ekonomi, produsen tersebut juga membantu kinerja neraca berjalan. Oleh karena itu, kita harus bisa menghadapi Masyarakat Ekonomi ASEAN ini dengan baik. Jangan sampai kita ini terjerumus perekonomian dengan adanya MEA di ASEAN. Dalam mengahadapi Masyarakat Ekonomi ASEAN ini dengan menggunakan islamic marketing yang sesuai

Dunia semakin hari terus berjalan menyesuaikan zaman. Asia tenggara yang tergabung dalam ASEAN dengan memperkuat hubungan antar negara. Hubungan yang terjalin biasanya diwujudkan dalam bentuk kerjasama di beberapa bidang, salah satunya bidang ekonomi. Saat ini beberapa negara ASEAN menunjukkan perkembangan signifikan, bahkan posisinya termasuk yang diperhitungkan di wilayah Indonesia, Thailand, Vietnam, Malaysia, dan Singapura. Negara-negara tersebut kini bukan konsumen, melainkan juga negara produsen bagi negara-negara lain. Keberadaan uni eropa dan perjanjian perdangan bebas mereka utara mendorong negara-negara ASEAN menggagas kerjasama dalam bidang ekonomi Masyarakat Ekonomi ASEAN (MEA). Digagas untuk membentuk pasar tunggal dan menciptakan kondisi yang kompetitif antar negara demi peningkatan negara-negara anggota. Globalisasi tidak mungkin dihindari saat ini. Kemajuan teknologi informasi terutama pengguna internet kini kian meluas, membawa dapat praktisi membawa dampak dalam transaksi antar negara.

\section{IV.KESIMPULAN}

Temuan yang di dapat dari penelitian ini adalah ada beberapa cara untuk mengatasi dengan menggunakan asumsi Islamic Marketing dalam menghadapi Masyarakat Ekonomi ASEAN (MEA). Islam adalah agama yang diajarkan oleh Nabi Muhammad SAW. Berpedoman pada kitab suci Al-Quran yang diturunkan ke dunia melalui wahyu Allah SWT. Pemasaran penilaian strategi pemasaran, jasa, fungsi, dan hasilnya. Konsep Pemasaran Islam dapat dianalisis dan dibangun dari filosofi yang bersumber pada tujuan motif dasar pada penciptaan manusia. Islam merupakan agama yang lengkap dan mengatur kehidupan manusia (QS3: 19, QS 16: 52, QS98: 5, dan QS110: 2). Islamic marketing harus bertumpu pada empat prinsip dasar ketuhanan (rabbaniyyah), menjunjung akhlak tinggi mulia (akhlaqiyyah), mewaspadai pasar yang selalu berubah (waqi'iyah), dan selalu berorentasi untuk memartabatkan manusia (al-insaniyyah). Menurut Hermawan dan Syafi'i menunjukan tujuh belas setrategi untuk mengimplementasikan prinsip-prinsip diatas. Strategi tersebut antara lain meliputi mengembangkan spritual-based organisation, menunjukan respek yang tinggi terahadap pesaing, mencermati global paradoks nasabah, harus jeli dalam menentukan ceruk pasar (segmentation), mampu mencuri hati dan jiwa nasabah (customer's heart and soul) yang mampu untuk menjadi beda dalam hal konten dan kontek penggarapan pasar, bersikap transparan, mengayuhkan nilai tambah yang proporsional kepada segenap stakeholders, jujur dalam memberikan marketing-mix (barang, harga, promosi, pengiriman, dan layanan purna-jual) serta mengembangkan budaya yang etis dan bermoral. Supaya bisa dijadikan pedoman untuk pemasaran secara islami yang benar.

Penelitian ini mempunyai keterbatasan obyek penelitian, terbatas pada beberapa informasi yang ada saat ini Islamic Marketing untuk menghadapi Masyarakat Ekonomi ASEAN (MEA). Supaya lebih baiknya harus diperhatikan asumsi Islamic Marketing agar tidak terjadi hal yang tidak diinginkan.

\section{DAFTAR PUSTAKA}

Ahmad, M. (1995). Business Ethics In Islam, IIIT, Islam abad.

Arham, M. (2010). Islamic Perspectif on Markerting. Journal of Islamic Marketing. 1(2), 126.

Alizade, R., Mehreni, H., \& Didekhani, H. (2014). A Study on The Effect of Selected Marketing Mix Element on Brand Equity with Mediating Role of Brand Equity in Etika Chain Stores-Golestan Province. Kuwait Chapter of the Arabian. Journal of Businness and Mangement Review, 3(11A), 184. http://www.arabianjbmr.com/pdfs/KD_VOL_311a/23.pdf.

Boy, Samsul Bakhri. (2015). Masyarakat Ekonomi ASEAN (MEA) dan Tinjauan dari Perspektif Ekonomi Syariah. Jurnal Ekonomi, Manajemen dan Akuntansi Vol. 25 No. 2.

Djavlonbek, Kadirov. (2014). Islamic Marketing as Macro Marketing. Journal of Islamic Marketing, Vol. 5 Issue: 1, pp.2-19. http://dx.doi.org/10.1108/JIMA09-2012-0054

Farell, K. (2011). Human Resource Issue as Barriers to Staff Retention and Development in the Tourism Industry. Irish Journal of Management, 22(2), 121. http://wwwsearcch.proquest.com/openview/b692bba6a8ef4dc5d82ea7c547d3168/1 ?pq-origsite=gscholar\&cbl=10069.

Jonathan A.J. Wilson, John Grant. (2013). Islamic Marketing - a Challenger to the Classical Marketing Canon?, Journal of Islamic Marketing, Vol. 4 Issue: 1, pp.7-21, doi: 10.1108/17590831311306327.

Kotler, P. dan Armstrong, G. (2006). Principles of Marketing. New Jersey: prentice Hall Inc. http://english4success.ru/Upload/books/584.pdf.

Kartajaya, Hermawan dan Dr. Muhammad Syafi'i Antonio. (2006). Syariah Marketing. PT Mirzan Pustaka Anggota IKAPI.

Nilam, Sari. Manajemen Marketing (Pemasaran) Produk Jasa Keuangan Perbankan Dalam Perpekstif Islam. IAIN Ar-Raniry Darusslam, Banda Aceh. 